\title{
Prevalence and Factors Associated with Undernutrition among Exclusively Breastfeeding Women in Arba Minch Zuria District, Southern Ethiopia: A Cross-sectional Community-Based Study
}

\author{
Hadiya Hassen Tikuye ${ }^{1}$, Samson Gebremedhin ${ }^{2}$, Addisalem Mesfin ${ }^{1}$, Susan \\ Whiting $^{3^{*}}$
}

OPEN ACCESS

Citation: Hadiya Hassen Tikuye, Samson Gebremedhin, Addisalem Mesfin, Susan Whiting. Prevalence and Factors Associated with Undernutrition among Exclusively Breastfeeding Women in Arba Minch Zuriya District, Southern Ethiopia: A Cross-sectional Community-Based Study. Ethiop J Health Sci. 2018;29(1):913.

doi:http://dx.doi.org/10.4314/ejhs.v29i1.13 Received: August 9, 2018

Accepted: August 15, 2018

Published: January 1, 2019

Copyright: (C) 2018 Hadiya Hassen. This is an open access article distributed under the terms of the Creative Commons Attribution License, which permits unrestricted use, distribution, and reproduction in any medium, provided the original author and source are credited.

Funding: Nil.

Competing Interests: The authors declare that this manuscript was approved by all authors in its form and that no competing interest exists.

Affiliation and Correspondence:

${ }^{1}$ School of Nutrition, Food Science and Technology, College of Agriculture, Hawassa University, Hawassa Ethiopia

${ }^{2}$ School of Public Health and Environmental Health, Hawassa University, Hawassa Ethiopia ${ }^{3}$ College of Pharmacy and Nutrition, University of Saskatchewan, Saskatoon Canada

*Email: susan.whiting@usask.ca

\section{ABSTRACT}

BACKGROUND: In developing countries, women are generally vulnerable to undernutrition especially during lactation because of inadequate nutrient intake. The purpose of this study was to assess the prevalence of underweight, associated factors and mean dietary intake of selected nutrients among lactating women in Arba Minch Zuriya districts, Gamo Gofa, Ethiopia

METHODS: Multistage cluster sampling technique was used to select 478 exclusively breastfeeding women. Data was collected by using structured questionnaire, and weight and height measurements. Mean intake of calories, calcium, iron, zinc and vitamin $A$ was assessed by using 24-hour recall method on subsample of 73 subjects and compared against the Ethiopian and African food composition tables. Logistic regression analysis was used to evaluate the association between various independent variables and maternal underweight.

RESULTS: The prevalence of underweight was 17.4\%. Maternal underweight significantly associated with short birth to pregnancy interval, high workload burden, household food insecurity, less access to nutrition information and low level of women educational status.

CONCLUSIONS: A significant proportion of women suffered from undernutrition and the mean intake of calories, calcium and zinc were below the recommended level for lactating women. Hence, to improve nutritional status of lactating women, strategies should focus on nutrition counseling, improvement in women's access to labour saving technologies and effective household food security interventions

KEYWORDS: Lactating women, underweight, nutrient intake, breastmilk, micronutrients

\section{INTRODUCTION}

Factors such as lack of control over resources, suboptimal dietary practices, lack of education and poor access to nutrition information compromise nutritional status of girls and women in less developed countries $(1,2)$. In addition, the high workload burden of women in households and in agricultural activities increases their likelihood of 
being malnourished (3). Further, women in low income countries are at a greater risk of not meeting their nutrient requirements $(4,5)$. In SubSaharan Africa the prevalence of chronic energy deficiency among women is $10-20 \%$ (6). In low income countries including Ethiopia, $20-25 \%$ of women are underweight $(7,8)$. Household food insecurity, low dietary diversity score, low level of educational status and high burden of reproduction were reported as determinants of maternal undernutrition in Ethiopia (8).

There are increased physiological needs during lactation, reflected in higher nutritional requirements. Failure to gain the necessary weight has a negative impact on maternal health as well as milk quality and quantity $(9,10)$. Thus, measuring the prevalence of undernutrition through dietary intakes and measurement of body weight status during lactation can assist in determining the underlying factors.

There is limited data on prevalence of maternal undernutrition among lactating women in Ethiopia. In Jimma, prevalence of $40.6 \%$ was reported (11), and in Tigray, it was less, at $25 \%$ (12). Poor food intake manifest as low diet diversity score was identified as a main predictor of maternal underweight (11). In contrast, external factors such as size of farm land, length of years of marriage, maize cultivation, frequency of antenatal care visit and age of breastfeeding child were identified (12). The micronutrients of concern during lactation are zinc, calcium, vitamin $A$ and vitamin $C$ (12). By understanding the link between intake and barriers to adequate intake, it may be possible to correct undernutrition in lactating women in Ethiopia.

To address lack of information on nutrition needs of lactating women in Ethiopia, this study set out to assess the magnitude of undernutrition among exclusive breastfeeding women and to determine important contributing factors including usual dietary practices. In Arba Minch Zuriya districts where the research is conducted, studies regarding nutrition in lactating women are very limited. The nutritional status as affected by dietary practices and other contributing factors of underweight among the lactating women from this study can be added to existing evidence in Ethiopia to use for policy development.

\section{METHODS}

Study area: Arba Minch Zuriya is a rural administrative district in the Gamo Gofa zone and is located $505 \mathrm{~km}$ away from Addis Ababa. The district has 29 kebeles, with a total estimated population of 200,000 . The total number of reproductive age women in the study area was 27,202 of which there were 5140 who were lactating (13). The mean annual daily temperature ranges 15.1 to $25.0^{\circ} \mathrm{C}$. Maize, sorghum, wheat, barley and teff are the primary crops are produced. Moringa stenopetella and kale are among the most consumed staple vegetables; common fruits are banana and mango. According to the woreda office, seven health centers and 29 health posts provide health services for the community.

Study design and sample: This was a community-based cross-sectional study with both descriptive and analytic elements, carried out from May to June 2015. The study population comprised women who had given birth within six months prior to data collection and were living in randomly selected kebeles of the study area. Women who had gave birth less than 45 days at the time of recruitment, those who were seriously ill and the ones who could not be found at home after three consecutive visits were excluded. Sample size was determined using single population proportion formula. The inputs were a $95 \%$ of confidence level, a $5 \%$ of margin of error, a $25 \%$ estimated prevalence of maternal underweight (12), a design effect of 1.5 and a $10 \%$ of non-response rate. The sample size was found as 478 .

Sampling procedure: A Multistage cluster sampling procedure was followed. The kebeles in the district were stratified to Woinadega, Kola and Dega agroecology areas. Then, the total sample size was divided to the three strata proportionally to their population size. From each stratum, eight kebeles (4 from Woinadega, 3 from Kola and 1 from Dega) were selected at random and the sample size for each stratum was distributed to the kebeles proportional to their population size. Sampling frame was prepared for each household

DOI: http://x.doi.org/10.4314/ejhs.v27i8.13 
with lactating women, who were identified with the help of health development army. Study subjects were selected using systematic random sampling.

\section{Data collection procedures and quality} assurance: The structured questionnaire was derived from different standard questionnaires $(14,18)$. The questionnaire was prepared in English. The final version was translated into Amharic and then re-translated into English. Diploma teachers who were good at Amharic and local languages (Gamogna and Zeisegna) were recruited. The questionnaire included sociodemographic, socio-economic, health and reproductive history and dietary intake/diversity.

A food frequency questionnaire listing food groups consumed the previous day was used to calculate dietary diversity score (DDS) of lactating women. DDS was calculated as the number of food groups out of a possible nine were consumed over the past 24 hours. A high dietary diversity was considered if $\geq$ six food groups, medium if 4 four to five 5 food groups and low if $\leq$ three or less food groups (15) were consumed in the specified period. A repeated quantitative 24-hour dietary recall was used to collect quantitative data from sub-sample of 73 study participants $(15 \%$ of total sample size) (16) to assess mean intake of calorie, calcium, zinc, iron and vitamin A. To account for the 'day of the week effects' one weekday and one market day were represented.

Anthropometric data was collected by measuring weight and height of lactating women using calibrated equipment and standardized techniques $(16,17)$. Weight was measured to the nearest $0.1 \mathrm{~kg}$ using a digital scale. Height was measured to the nearest $0.1 \mathrm{~cm}$ with a fixed stadiometer with vertical backboard and movable headboard. Measurements were taken with the women standing erect with feet parallel and buttocks, shoulders and back of head touching the wall. Body Mass Index (BMI) was calculated as weight $(\mathrm{kg})$ divided by height squared $\left(\mathrm{m}^{2}\right)$. Subjects were classified as underweight if BMI < 18.5 (17).

The Food and Nutrition Technical Assistance (FANTA) household food insecurity access scale (HFIAS) was used to assess household food security (18). The tool had nine questions each having four answer options in a recall period of 30 days. The precoded options were never ( 0 points), rarely (once or twice in the past 4 weeks; 1 point), sometimes (three to ten times in the past 4 weeks; 2 points), and often (more than ten times in the past 4 weeks; 3 points). Scores for answers to these questions were summed (0-27) and households classified as four level of household food insecurity. The higher the score, the more food insecurity a household experienced.

Food security was defined as follows. Households who experienced none of the food insecurity conditions were categorized as "food secure", but household worries about not having enough food sometimes or often in the last four weeks were "mildly food insecure". A "moderately food insecure" household sacrificed quality more frequently, by eating monotonous diet or undesirable foods sometimes or often, but did not experience any of the severe conditions (running out of food, going to bed hungry, or going a whole day and night without eating) which are characteristic of "severely food insecure" households.

To assure data quality, training was given to data collectors and supervisors on all procedures. Pretest was carried out on 5\% of the study sample on kebeles not included in this study. Data collectors' accuracy of anthropometric measurements was standardized prior to the study. The principal investigator supervised all data collection. Filled copies of the questionnaire were checked for their completeness every day after data collection.

Ethical clearance was obtained from the Institutional Review Board of Hawassa University, College of Medicine and Health Sciences. Further permission was obtained from Arba Minch Zuriya Woreda Health Office, and explanation about the purpose of the survey and the benefits was provided to study participants in order to obtain their verbal or written consent. Confidentiality of the data was maintained.

The independent variables were socioeconomic factors, household food insecurity, family size, housing condition, work load, parity, birth to pregnancy interval, frequency of breast feeding, meal frequency, dietary diversity, antenatal care, place of delivery and access to

DOI: http://dx.doi.org/10.4314/ejhs.v28i5.13 
nutrition information during pregnancy or postpartum. The dependent variables were work load, parity, birth to pregnancy interval, frequency of breast feeding, meal frequency, dietary diversity, antenatal care, place of delivery and access to nutrition information $(12,19)$.

Data analysis: Tolerance test $<2$ was used to check the absence of multi-co-linearity. Variables were checked for normality using KolmogorovSmirnove test (20). Descriptive summaries, frequencies and proportions were found. Logistic regression was employed to assess the association between dependent and independent variables. Odds ratio (OR) with $95 \%$ CI was used to assess strength of association, and p-value $<0.05$ was statistical significance. The amount of consumed foods and drinks obtained from repeated $24 \mathrm{hr}$ recall data was converted to grams. Nutrients values were computed using Ethiopian (21) and African (22) food composition tables. Since the data was not normally distributed, median energy and nutrient intake values were computed and compared with the recommended dietary intake (RDA) for lactating women $(23,24)$.

Wealth index was computed using principal component analysis (PCA) as a composite indicator of living standard, initially based on 19 variables related to ownership of valuable assets, livestock, size of agricultural land and materials used for house construction (13). A score of " 1 " was given for each of 14 binary variables; for the remaining five variables, different scoring systems were used. Variables (sources of water, sanitary facility and ownership of kerosene) were removed from analysis as they had low communality score. Five categories (poorest, poorer, middle, richer and richest) were generated as approximately equal quintiles.

In order to identify factors associated with maternal underweight, logistic regression analysis was used. Two models were developed separately for proximal and distal independent variables. Variables at binary logistic analysis with a p-value of less than 0.25 were subsequently included in the multivariate analysis. The adequacy of the model was checked by using Hosmer and Lemeshow goodness of fit test (20).

\section{RESULTS}

Socio-demographics: Data for subjects (478 exclusively breast-feeding women) is in Table 1 . The mean age $( \pm \mathrm{SD})$ was $24.8 \pm 4.3$ years. About half $(52.9 \%)$ of the participants were illiterate. The magnitude of mild, moderate and severe food insecurity was $28.2,33.1$ and $13.4 \%$, respectively. The majority $(84.1 \%)$ of the households had monthly incomes below 500 Ethiopian birr (\$25USD).

Knowledge about nutrition: More than half $(51.3 \%)$ of the respondents received no nutrition information from health extension workers during pregnancy or postpartum period. Less than half $(42.7 \%)$ knew the meaning of diversified diet. More than half $(61.5 \%)$ knew that women should increase their number of meals while breastfeeding. Only 18\% correctly answered the desired meal frequency i.e., $\geq$ five meals per day. Only about half (53.6\%) knew why consuming the extra meal was necessary.

Health status and service utilization: The majority $(95.4 \%)$ of the participants had antenatal follow-up, and more than half (61.5\%) gave birth at a health facility. About $15.3 \%$ had history of disease within the last one month prior to the survey, including malaria, typhoid fever, diarrhea and gastritis or breast disease.

Reproductive history and workload: The majority $(83.4 \%)$ of the study participants had $\geq 2$ children preceding the survey $(2.92 \pm 1.73)$. Birthto-pregnancy interval history was assessed for the $52.3 \%$ who had at least two previous births; their birth-to-pregnancy interval was less than 24 months. Most women (88.7\%) breastfed their children 8 to 12 times per day.

Labor-intensive activities included agricultural work, walking to market, collecting fuel wood, fetching water, and employment activities. Some women (30.8\%) had "high" workload The mean $( \pm \mathrm{SD})$ working hours of labor was $16.9 \pm 2.1$ per week. This increased energy expenditure.

DOI: http://dx.doi.org/10.4314/ejhs.v27i8.13 
Table 1: Socio-demographic characteristics of studied lactating women $(n=478)$ in Arba Minch Zuria districts, July 2015.

\begin{tabular}{lll}
\hline Variables & Frequency & Percentage \\
\hline Age (y) & & \\
15-24 & 193 & 40.4 \\
$25-34$ & 275 & 57.7 \\
$\geq 35$ & 9 & 1.9 \\
Marital status & 461 & 96.4 \\
$\quad$ Married & 15 & 3.2 \\
$\quad$ Single & 2 & 0.4 \\
$\quad$ Divorced/separated & 445 & 51.3 \\
Educational status of the women & 8 & 1.7 \\
$\quad$ Illiterate & 163 & 34.1 \\
$\quad$ Read and write & 62 & 12.9 \\
$\quad$ Primary education & & \\
$\quad$ Secondary or above education & 230 & 49.9 \\
Educational status of husband(n=461) & 13 & 2.8 \\
$\quad$ Illiterate & 108 & 23.4 \\
$\quad$ Read and write & 17 & 3.6 \\
$\quad$ Primary education & & \\
$\quad$ No information & 230 & 48.1 \\
Ownership of agricultural land & & \\
$\quad$ Yes & & \\
\hline
\end{tabular}

Dietary intake: More than half $(54.7 \%)$ of participants reported that they mostly consumed three or less meals per day, whereas only $18.0 \%$ of the women reported having five or more meals per day. The mean $( \pm \mathrm{SD})$ dietary diversity score of breast-feeding women was $4.27 \pm 1.19$. Two-thirds $(61.7 \%)$ reported consuming four to five food groups over 24 hours. Almost all (99.8\%) participants consumed cereal-based foods, mainly maize, teff, sorghum, wheat and barley. Most participants $(93.1 \%)$ consumed dark green leafy vegetables, commonly kale and moringa. Foods rarely eaten were egg $(7.7 \%)$, organ meats $(6.1)$ and flesh meats $(6.1 \%)$ (Table 2).

Table 2: Food groups consumed in the 24 hours preceding the survey by lactating women in Arba Minch Zuria districts, July 2015.

\begin{tabular}{lll}
\hline Food groups & Frequency & Percentage \\
\hline Cereals, root and tubers & 477 & 99.8 \\
Green leafy vegetables & 437 & 91.4 \\
Other fruits and vegetables & 374 & 78.0 \\
Legumes and nuts & 249 & 62.9 \\
Vitamin A rich vegetables & 225 & 57.5 \\
Milk and milk products & 129 & 25.9 \\
Egg & 38 & 7.9 \\
Organ meat (liver, kidney, heart) & 29 & 6.1 \\
Flesh meats (beef, lamb, chicken.) & 29 & 6.1 \\
\hline
\end{tabular}

Nutrient intake: Most women $(84.9 \%)$ had median intakes of zinc that were below recommended; and more than half had median intakes of energy $(57.4 \%)$ and calcium $(54.3 \%)$ below the recommended. Most women met iron $(94.5 \%)$ and vitamin A $(79.5 \%)$ recommendations, (Table 3).

DOI: http://dx.doi.org/10.4314/ejhs.v28i5.13 
Table 3: Median $\left(25^{\text {th }} \& 75\right.$ th percentile $)$ nutrient intakes of lactating women in Arba Minch Zuria woreda, July, $2015(\mathrm{n}=73)$

\begin{tabular}{lccc}
\hline \multicolumn{1}{c}{ Nutrients } & $\begin{array}{c}\text { Median value } \\
\left(25^{\text {th }}, 75^{\text {th }} \text { percentile }\right)\end{array}$ & RDA\# & $\begin{array}{c}\text { Percentage } \\
\text { inadequate }\end{array}$ \\
\hline Food energy (kcal) & $2285(1936,2882)$ & 2365 & 57.5 \\
Calcium (mg) & $985(816,1204)$ & 1000 & 54.3 \\
Iron (mg) & $78(29,126)$ & 10 & 5.5 \\
Zinc (mg) & $9(7,11)$ & 12 & 84.9 \\
Vitamin-A (RE) & $1653(925,2312)$ & 850 & 21.9 \\
\hline
\end{tabular}

\# FAO/WHO $(22,23) \mathrm{RE}=$ retinol equivalents $(\mathrm{mcg})$

Nutritional status: Underweight $(\mathrm{BMI}<18.5)$ was seen in $17.4 \%$ of women. While $18.8 \%$ had BMI of $\geq 25$ indicating overweight, BMI was not intended to be used in lactating women to measure "excess" body weight.

Factors associated with undernutrition: Two models were prepared to examine the association of maternal undernutrition with independent variables. Frequency of breastfeeding, DDS, meal frequency, history of illness, birth-to-pregnancy interval, workload and parity were considered as proximal factors. Birth-to-pregnancy interval and workload had significant associations with maternal energy intake or expenditure. The odds of underweight among those who had pregnancy intervals less than 24 months were 2 times more likely to be underweight than those who had longer intervals $(\mathrm{AOR}=2.9)$. Similarly, the odds of underweight were three times higher in women who had workload burden $(\mathrm{AOR}=3.75)$ as compared to their counterparts (Table 4).

Table 4: Multivariable logistic regression analysis output on proximal factors associated with undernutrition of lactating women, July 2015.

\begin{tabular}{|c|c|c|c|c|}
\hline \multirow[t]{2}{*}{ Variables } & \multicolumn{2}{|c|}{ Underweight } & \multirow[t]{2}{*}{ COR (95\% CI) } & \multirow[t]{2}{*}{ AOR (95\% CI) } \\
\hline & No & Yes & & \\
\hline \multicolumn{5}{|c|}{ Birth to pregnancy interval* } \\
\hline$\leq 23$ months & 80 & 42 & $3.86(1.99-7.45)$ & $2.93(1.47-5.85)$ \\
\hline$\geq 24$ months $\ddagger$ & 214 & 16 & 1 & 1 \\
\hline \multicolumn{5}{|l|}{ Workload } \\
\hline Light & 303 & 28 & 1 & 1 \\
\hline High & 92 & 55 & $6.22(3.10 .34)$ & $3.75(2.02-6.99)$ \\
\hline \multicolumn{5}{|l|}{ History of illness } \\
\hline Yes & 51 & 22 & $2,43(1.37-4.29)$ & $1.72(0.81-3.67)$ \\
\hline Noț & 344 & 61 & 1 & 1 \\
\hline \multicolumn{5}{|l|}{ Dietary diversity } \\
\hline$\leq 3$ food groups & 91 & 35 & 1 & 1 \\
\hline $4-5$ food groups & 252 & 42 & $0.42(0.25-0.71)$ & $0.53(0.27-1.04)$ \\
\hline$\geq 6$ food groups & 52 & 6 & $0.29(0.11-0.75)$ & $0.55(0.12-1.72)$ \\
\hline \multicolumn{5}{|l|}{ Meal frequency } \\
\hline$\leq 2$ meals per day & 28 & 2 & $3.35(0.78-14.42)$ & $2.61(0.53-12.81)$ \\
\hline 3-4 meals per day & 75 & 70 & $2.05(0.42-9.84)$ & $2.15(0.38-12.06)$ \\
\hline$\geq 5$ meals per day $\ddagger$ & 292 & 11 & 1 & 1 \\
\hline
\end{tabular}

*Calculated among mothers who had two or more children, $\mathrm{COR}=$ Crude odds ratio, $\mathrm{AOR}=$ Adjusted odds ratio treference variable

DOI: http://dx.doi.org/10.4314/ejhs.v27i8.13 
Women's education, nutrition information, household food insecurity and wealth index were distal independent variables. After multivariable logistic regression, women's education and household food insecurity were significantly associated with maternal underweight $(\mathrm{p}<0.05)$. Those lactating women who received nutrition information either prior or during postpartum were $73 \%$ less likely to be underweight than those who had no nutrition information $(\mathrm{AOR}=0.27)$. Women who did not attend formal education were two times more likely to be underweight compared to those who had formal education ( $\mathrm{AOR}=2.31$ ). Further, women from food insecure households were three times more likely to be underweight compared to those lactating women from food secure households (AOR=3.04) (Table 5).

Table 5: Multivariable logistic regression analysis output on distal factors associated with undernutrition of lactating women, July 2015.

\begin{tabular}{|c|c|c|c|c|}
\hline \multirow[t]{2}{*}{ Variables } & \multicolumn{2}{|c|}{ Undernutrition } & \multirow[t]{2}{*}{ COR $(95 \% \mathrm{CI})$} & \multirow[t]{2}{*}{ AOR (95\%CI) } \\
\hline & No & Yes & & \\
\hline \multicolumn{5}{|l|}{ Nutrition information } \\
\hline Yes & 223 & 22 & $0.29(0.18-0.50)$ & $0.27(0.15-0.48)$ \\
\hline No & 172 & 61 & 1 & 1 \\
\hline \multicolumn{5}{|l|}{ Place of birth } \\
\hline Health institution & 257 & 46 & 1 & 1 \\
\hline Home & 138 & 37 & $2.37(1,43-3.74)$ & $1.59(0.93-2.69)$ \\
\hline \multicolumn{5}{|l|}{ Food security status } \\
\hline Food secure & 104 & 17 & 1 & 1 \\
\hline Food insecure & 281 & 66 & $3.43(1.66-7.07)$ & $3.04(1.37-6.71)$ \\
\hline \multicolumn{5}{|l|}{ Wealth index } \\
\hline Richest & 85 & 10 & 1 & 1 \\
\hline Rich & 83 & 14 & $0.27(0.12-0.59)$ & $0.43(0.18-1.020$ \\
\hline Middle & 80 & 15 & $0.39(0.19-0.79)$ & $0.54(0.25-1.12)$ \\
\hline Poor & 80 & 15 & $0.43(0.21-0.87)$. & $0.49(0.23-1.06)$ \\
\hline Poorest & 67 & 29 & 1 & 1 \\
\hline \multicolumn{5}{|l|}{$\begin{array}{l}\text { Women educational } \\
\text { status }\end{array}$} \\
\hline Informal education & 202 & 60 & $2.73(1.62-4.59)$ & $2.31(1.31-4.06)$ \\
\hline Formal education $\ddagger$ & 193 & 23 & 1 & 1 \\
\hline
\end{tabular}

*Calculated among mothers who had two or more children, $\mathrm{COR}=$ Crude odds ratio, $\mathrm{AOR}=$ Adjusted odds ratio treference variable

\section{DISCUSSION}

The prevalence of maternal underweight $(17.4 \%)$ is much lower than the findings from Jimma (11) and slightly lower than in Tigray (12). The high prevalence $(40.6 \%)$ of underweight among lactating women in Jimma occurred where women were enrolled in a nutrition intervention project. In our study area, farmers produced incomegenerating fruit (banana, mango), thus were less disadvantaged. Overall, short birth-to-pregnancy interval, workload burden, low wealth index, household food insecurity and less nutrition information were factors significantly associated with underweight.

The maternal depletion syndrome hypothesizes that mothers with a short birth-topregnancy interval do not have adequate time to replenish macro- and micro-nutrients (25). Indeed, in rural Nigeria, a higher risk of underweight was observed in those women who conceived before 23 months after a previous birth (26). A systematic review (25) revealed reduced maternal

DOI: http://dx.doi.org/10.4314/ejhs.v28i5.13 
fat stores in those who have short birth-topregnancy interval.

Workload due to labour intensive activities increased the risk of women's underweight by three-fold. Engaging in high physical activity is a burden for women as it increases energy expenditure. Similarly, a study done among lactating Senegalese women (27) shows weight loss due to negative energy balance associated with agricultural labour.

Food insecurity is a major challenge for Ethiopia especially in women and children (28). In this study, women from food secure households had a better nutritional status compared to women from food insecure households, consistent with other Ethiopian studies (29).

Women who got counseled on nutrition were $73 \%$ less likely to have low BMI. The result is supported by a study done in Addis Ababa that found improved dietary practices of pregnant women after nutrition education intervention (30).

Women's educational status was reported as a determinant of women's malnutrition $(31,32)$ in developing countries, as we found. The reason might be the fact that unemployment, low income and low decision making power of illiterate women made them less likely to access nutritious food.

According to Food and Agriculture Organization (23), lactating women should increase their energy intake by a minimum of 550 kcal to compensate for the cost of energy due to lactation. However, the median energy intake of lactating women in this study was lower than this standard, as also reported in the Tigray study (12). This low median caloric intake might be related to insufficient number of meals per day, which was reported in the study by $82 \%$.

Some micronutrient intakes were low, such as calcium and zinc. These are nutrient concerns among Ethiopian and other sub-Saharan women $(8,32)$. Mean vitamin A intake was higher than the recommendation, in contrast to findings in Tigray (12). However, the Ethiopian Food Consumption Survey (33) reported SNNPR as having higher than average vitamin $\mathrm{A}$ intakes due to availability of vitamin A rich fruits and vegetables. Similar to other studies, data on dietary iron consumption of Ethiopian women (33), and in particular lactating women (12), dietary iron consumption for most of lactating women in this study was adequate.

Limitations include conducting dietary assessment using only two days of participant intakes in a sub-sample, which might not indicate the usual intake. This study is cross-sectional wherein one cannot assume a cause and effect relationship. Additionally, body mass index was measured in women who may not have attained their pre-pregnancy weight, and therefore, we may have under-estimated underweight $(\mathrm{BMI}<18.5)$ prevalence.

In conclusion, close to one-sixth of the studied exclusively breastfeeding women were underweight. Most women had inadequate intakes of energy, calcium and zinc. The factors associated with maternal underweight were short birth-to-pregnancy intervals, high domestic and farm workload, low level of education, household food insecurity and limited exposure to nutrition information. Hence, health extension workers should give routine nutrition counseling, during these critical periods, about dietary practices, optimal birth spacing and its nutritional outcomes for the child and the women dietary practices and optimal birth spacing. Emphasis should be given to labour saving technologies for women to reduce the work burden, enhance household food security and women education in order to improve the nutritional status of women.

\section{REFERENCES}

1. Lartey A. Maternal and child nutrition in Sub-Saharan Africa: challenges and interventions. Proc Nutr Soc 2008; 67: 1058.

2. FAO. Gender Equality and Food Security. Women's Empowerment as a Tool against Hunger. Mandaluyong City, Philippines: Asian Development Bank. 2013.

3. Elder L, Ransome E. Nutrition of Women and Adolescent Girls: Why It Matters. 2003. Available at: https://www.prb.org/nutritionofwomenandad

DOI: http://dx.doi.org/10.4314/ejhs.v27i8.13 
olescentgirlswhyitmatters/ Accessed April 4, 2018.

4. Lee SE, Talegawkar SA, Merialdi M, Caulfield LE. Dietary intakes of women during pregnancy in low- and middleincome countries. Publ Hlth Nutr 2012; 16: 1340-53.

5. Harika R, Faber M, Samuel F, Kimiywe J, Mulugeta A, Ans Eilander A. Micronutrient status and dietary intake of iron, vitamin A, iodine, folate and zinc in women of reproductive age and pregnant women in Ethiopia, Kenya, Nigeria and South Africa. Nutrients. 2017;9(10). pii: E1096. doi: 10.3390/nu9101096.

6. Save The Children. State of the World's Mothers: Nutrition in the First 1,000 Days. 2012. Available at: https://resourcecentre.savethechildren.net/lib rary/state-worlds-mothers-2012-nutritionfirst-1000-days Accessed April 4, 2018.

7. Chaparro C, Oot L, and Sethuraman K. Overview of the Nutrition Situation in Seven Countries in Southeast Asia. FANTA III. 2014 Available at: https://www.fantaproject.org/sites/default/fil es/download/Southeast-Asia-NutritionOverview-Apr2014.pdf Accessed April 4, 2018.

8. Ferede A, Lemessa F, Tafa M, and Sisay S. The prevalence of malnutrition and its associated risk factors among women of reproductive age in Ziway Dugda district, Arsi Zone, Oromia, Ethiopia. Publ Hlth $J$ 2017; 152: 1-8.

9. Alam DS, vanRaaij JMA, Hautvast JG, Yunus M, Fuchs LG. Energy stress during pregnancy and lactation: consequences for maternal nutrition in rural Bangladesh. Eur $J$ Clin Nutr 2003; 57: 151-6.

10.Soliman SM, Soliman AM, Bakr MS. Relationships between maternal nutritional status, quantity and composition of breast milk in Egypt. Afr J Ag Sci Technol 2014; 2: 59-64.

11.Alemayehu M, Argaw A, Mariam AG. Factors Associated with Malnutrition among Lactating Women in Subsistence Farming Households from Dedo and Seqa-Chekorsa
Districts, Jimma Zone. Devel Country Studies 2015; 5: 21.

12.Haileslassie K, Mulugeta A, and Girma M. Feeding practices, nutritional status and associated factors of lactating women in Samre Woreda, South Eastern Zone of Tigray, Ethiopia. Nutr $J$ 2013; 12:28. doi: 10.1186/1475-2891-12-28.

13. Central Statistical Authority. Summary and Statistical Report of the 2007 Population and Housing Census Results. Addis Ababa, Ethiopia: CSA.2007.

14.Central Statistical Agency (Ethiopia) and ICF International Ethiopia Demographic and Health Survey 2011. Addis Ababa Ethiopia and Maryland, USA. 2012

15.Kennedy G, Ballard T, and Dop MC. Guidelines for Measuring Household and Individual Dietary Diversity.2011. Nutrition and Consumer Protection Division, Food and Agriculture Organization of the United Nations. Available at: http://www.fao.org/docrep/014/i1983e/i1983 e00.htm Accessed April 4, 2018.

16.Gibson RS. Principle of Nutritional Assessment $2^{\text {nd }}$ ed. University of Otago, Dunedin, New Zealand. 2005.

17. National Health and Nutrition Examination Survey (NHANES). Anthropometry procedures manual. Center for Disease Control (CDC). 200. Available at: https://www.cdc.gov/nchs/data/nhanes/nhane s_07_08/manual_an.pdf Accessed April 4, 2018 .

18. Coates J, Swindale A, and Bilinsky $P$. Household Food Insecurity Access Scale (HFIAS) for Measurement of Food Access: Indicator Guide FANTA version 3. 2007. Available at: https://www.fantaproject.org/sites/default/fil es/resources/HFIAS_ENG_v3_Aug07.pdf Accessed on April 4, 2018.

19.Hundera TD, Gemede HF, Wirtu D, and Kenie DN. Nutritional Status and Associated Factors among Lactating Mothers in Nekemte Referral Hospital and Health Centers, Ethiopia. Food Sci Qual Manage 2015; $35 . \quad$ Available at: 
http://www.iiste.org/Journals/index.php/FSQ M/article/view/19192/19387

20.Real Statistics Using Excel. Available at: http://www.real-statistics.com/logisticregression/hosmer-lemeshow-test/. Accessed April 4, 2018.

21.Ethiopia Health and Nutrition Research Institute (EHNRI). Food composition table for use in Ethiopia. Part IV. Addis Ababa: Ethiopia. Health and Nutrition Research Unit.1998.

22.FAO/ INFOODS/ WAHO . West African food composition table. Viale delle Terme di Caracalla, 00153 Rome, Italy 2012. Available at: http://www.fao.org/docrep/015/i2698b/i2698 b00.pdf

23.FAO/FANTA report series 1. Human Energy Requirements. report of the joint $\mathrm{FAO} / \mathrm{WHO} / \mathrm{UNU}$ expert consultation Rome 2004.

http://www.who.int/nutrition/publications/nu trientrequirements/9251052123/en/

24.FAO/WHO. Vitamin and mineral requirements in human nutrition. $2^{\text {nd }}$ edition 2004. Available at: http://apps.who.int/iris/bitstream/handle/106 65/42716/9241546123.pdf;jsessionid=0E3B 5415162BEBD5C17F52348F5BEA41?sequ ence $=1$

25.Conde-Agudelo A, Rosas A, Castaño F, and Norton M. Effects of birth spacing on maternal, perinatal, infant, and child health: a systematic review of causal mechanisms. Stud Fam Planning 2012; 43(2): 93-114.

26. Adebowale SA, Adepoju OT, and Fagbamigbe FA. Child spacing and parity progression: implication for maternal nutritional status among women. Pak J Nutr 2011; 10: 485-91.
27.Simondon KB, Ndiaye T, Dia M, Yam A, Ndiaye M, Marra A, Diallo A, and Simondo F. Seasonal variations and trends in weight and arm circumference of nonpregnant rural Senegalese women, 19901997. Eur J Clin Nutr 2008; 62: 997-1004.

28. Endalew B, Muche M, and Tadesse S. Assessment of food security situation in Ethiopia: A review. Asian J Ag Res 2015; 9: $55-68$.

29. Motbainor A, Worku A, and Kumie A. Household food insecurity is associated with both body mass index and middle upper-arm circumference of mothers in northwest Ethiopia: a comparative study. Int $J$ Women's Health 2017; 9: 379-89.

30.Zelalem A, Endeshaw M, Ayenew M, Shiferaw S, and Yirgu R. Effect of Nutrition Education on Pregnancy Specific Nutrition Knowledge and Healthy Dietary Practice among Pregnant Women in Addis Ababa. Clin Mother Child Health 2017; 14: 265.

31.Devgun P, Mahajan SL, and Gill KP. Prevalence of chronic energy deficiency and socio demographic profile of women in slums of Amritsar city, India. Int $J$ Res Hlth Sci.2004; 2(2): 527-32.

32.Mtumwa $\mathrm{AH}$, and Vuai S. Determinants of undernutrition among women of reproductive age in Tanzania mainland. $S$ Afr J Clin Nutr 2016; 29: 75-81.

33.Ethiopia Public Health Institute (EPHI). Ethiopian National Food Consumption Survey. Addis Ababa, Ethiopia. 2013. Available at: https://www.ephi.gov.et/images/pictures/Nat ional $\% 20$ Food $\% 20$ Consumption $\% 20$ Survey \%20Report Ethiopia.pdf Accessed April 5, 2018 